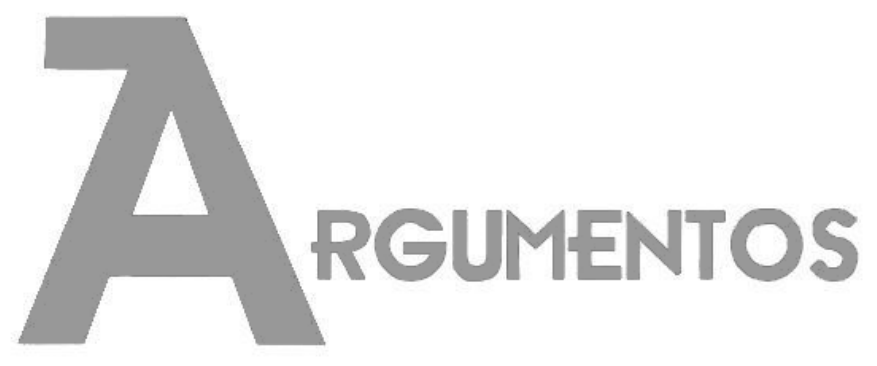

Vol. 16, n. 2, jul./dez. 2019 ISSN: 2527-2551 (online)

http://www.periodicos.unimontes.br/argumentos

\title{
O liberalismo social de Merquior: um contraste com o liberismo de F. A. Hayek para o contexto brasileiro
}

Anderson Barbosa Paz ${ }^{1}$

Recebido em: 11/05/2019

Aprovado em: 26/08/2019

Resumo: O presente artigo objetiva discutir alguns aspectos da reflexão e contribuição de Merquior, especialmente, seu liberalismo social, em contraste com o liberismo de F. A. Hayek. A importância desse trabalho se dá em dois sentidos. Em primeiro lugar, o pensamento e obra de Merquior tem singular importância, já que, como um ativista e intelectual político brasileiro, refletiu sobre a tradição, premissas e propostas do liberalismo clássico para o Estado brasileiro, historicamente marcado por um viés patrimonialista e estatizante. Seu cuidado e amplo conhecimento da história nacional o levou do liberismo de Von Mises e Hayek ao liberalismo social. Em segundo lugar, é possível afirmar que, no Brasil, a produção intelectual de Merquior não é tão difundida e estudada nas ciências sociais, possibilitando que esse texto contribua na divulgação do pensamento do sociólogo brasileiro. Em contraste, porém, estabelecer-se-á uma relação crítica entre o liberalismo social de Merquior com o liberismo de Hayek. À década de 80 , o autor brasileiro, assumidamente liberal, criticou vários aspectos do pensamento do economista austríaco, devido a suas considerações sobre as implicações de um liberismo hayekiano ser aplicado no Brasil. Considerar-se-á a importância da ação estatal na promoção de oportunidades para a expansão de uma liberdade efetiva em um país marcado pela desigualdade. O liberalismo social que pressupõe a tradição liberal como uma cosmovisão e que percebe o Estado como promovedor, ao lado do mercado, da liberdade, faz contraste ao liberismo hayekiano que reduz o liberalismo à liberdade econômica. É, assim, que as obras de Merquior e Hayek, suas convergências e divergências, constituem-se como um objeto de estudo singular para o contexto hodierno brasileiro.

Palavras-chave: J. G. Merquior; Liberalismo Social; F. A. Hayek; Liberismo.

\footnotetext{
${ }_{1}^{1}$ Mestrando em Ciência Política e Relações Internacionais pela Universidade Federal da Paraíba (UFPB), Brasil. Bacharel em LEA Negociações Internacionais pela Universidade Federal da Paraíba (UFPB), Brasil. Bacharelando em Direito pela Universidade Federal da Paraíba (UFPB), Brasil. E-mail: andersonbarbosapaz@gmail.com. ORCID: https://orcid.org/0000-0001-7799-3707.
} 


\title{
Liberalismo social de Merquior: un contraste con el librecambio de F. A. Hayek para el contexto brasileño
}

Resumen: Este artículo tiene como objetivo discutir algunos aspectos de la reflexión y contribución de Merquior, especialmente su liberalismo social, en contraste con el librecambio de F. A. Hayek. La importancia de este trabajo es bidireccional. En primer lugar, el pensamiento y el trabajo de Merquior es de singular importancia, ya que, como activista político e intelectual brasileño, reflexionó sobre la tradición, las premisas y las propuestas del liberalismo clásico para el estado brasileño, históricamente marcado por patrimonialismo y estatistismo. Su cuidadoso conocimiento de la historia nacional lo llevó del librecambio de von Mises y Hayek al liberalismo social. En segundo lugar, es posible afirmar que, en Brasil, la producción intelectual de Merquior no está tan extendida y estudiada en las ciencias sociales, lo que permite que este texto contribuya a la difusión del pensamiento del sociólogo brasileño. En contraste, sin embargo, se establecerá una relación crítica entre el liberalismo social de Merquior y el librecambio de Hayek. En la década de 1980, el autor brasileño, ciertamente liberal, criticó varios aspectos del pensamiento del economista austriaco por sus consideraciones sobre las implicaciones de un librecambio hayekiano aplicado en Brasil. Se considerará la importancia de la acción estatal en la promoción de oportunidades para la expansión de la libertad efectiva en un país marcado por la desigualdad. El liberalismo social, que presupone la tradición liberal como una visión del mundo, y que percibe al estado como un promotor de la libertad del mercado, contrasta con el librecambio hayekiano que reduce el liberalismo a la libertad económica. Así, las obras de Merquior y Hayek, sus convergencias y divergencias, constituyen un objeto de estudio singular para el contexto brasileño actual.

Palabras-clave: J. G. Merquior; Liberalismo social; F. A. Hayek; Librecambio.

\section{Merquior's social liberalism: a contrast with F. A. Hayek's liberism for the brazilian context}

\begin{abstract}
This article aims to discuss some aspects of Merquior's reflection and contribution, especially his social liberalism, in contrast to F. A. Hayek's liberism. The importance of this work is in two aspects. In the first place, Merquior's thought and work is of singular importance, as a Brazilian political activist and intellectual, he reflected on the tradition, premises and proposals of classical liberalism for the Brazilian state, historically marked by patrimonialism and statism. His careful knowledge of national history led him from von Mises and Hayek's liberism to social liberalism. Secondly, it is possible to state that, in Brazil, Merquior's intellectual production is not so widespread and studied in the social sciences, enabling this text to contribute to the dissemination of the thinking of the Brazilian sociologist. In contrast, however, a critical relationship will be established between Merquior's social liberalism and Hayek's liberism. In the 1980s, the admittedly liberal Brazilian author criticized various aspects of the austrian economist's thought for his considerations of the implications of a hayekian liberism being applied in Brazil. The importance of state action in promoting opportunities for the expansion of effective freedom in a country marked by inequality will be considered. Social liberalism, which presupposes the liberal tradition as a worldview, and which perceives the state as a market-side promoter of freedom, contrasts with the hayekian liberism that reduces liberalism to economic freedom. Thus, the works of Merquior and Hayek, their convergences and divergences, constitute a singular object of study for the Brazilian context today.
\end{abstract}

Keywords: J. G. Merquior; Social liberalism; F. A. Hayek; Liberism.

\section{Introdução}


Dossiê | O liberalismo social de Merquior: um contraste com o liberismo de F. A. Hayek para o contexto brasileiro (PAZ, Anderson Barbosa)

A tradição do pensamento liberal tem ampla gama de ramificações. Talvez, seja preciso falar de liberalismos. Essa corrente de pensamento político-econômico-social, porém, tem profundas raízes nos países europeus e nos de tradição anglo-saxônica. Importa que a reflexão das implicações dos princípios de uma ordem liberal seja criticamente refletida a partir do contexto de cada país. A importação das pressuposições e argumentos para a constituição de uma estrutura liberal para países que não passaram por revoluções burguesas e cujas culturas são não-liberais tem, no curso da história, causado gravames à coletividade. A reflexão sobre a tradição liberal no Brasil do século XX contou com a obra profícua do ensaísta e diplomata brasileiro José Guilherme Merquior (1941-1991).

O presente artigo objetiva discutir alguns aspectos da reflexão e contribuição de Merquior, especialmente, seu liberalismo social, em contraste com o liberismo de F. A. Hayek. A importância desse trabalho se dá em dois sentidos. Em primeiro lugar, o pensamento e obra de Merquior tem singular importância, já que, como um ativista e intelectual político brasileiro, refletiu sobre a tradição, premissas e propostas do liberalismo clássico para o Estado brasileiro, historicamente, marcado por um viés patrimonialista e estatizante. Seu cuidado e amplo conhecimento da história nacional o levou do liberismo de Von Mises e Hayek ao liberalismo social. Em segundo lugar, é possível afirmar que, no Brasil, a produção intelectual de Merquior não é tão difundida e estudada nas ciências sociais ${ }^{2}$, possibilitando que esse texto contribua na divulgação do pensamento do sociólogo brasileiro.

Em contraste, porém, estabelecer-se-á uma relação crítica entre o liberalismo social de Merquior com o liberismo de Hayek. À década de 80, o autor brasileiro, assumidamente liberal, criticou vários aspectos do pensamento do economista austríaco, devido a suas considerações sobre as implicações de um liberismo hayekiano ser aplicado no Brasil. Considerar-se-á a importância da ação estatal na promoção de

\footnotetext{
${ }^{2}$ Felipe (2014) comenta que há um triplo estigma político contra Merquior. "Em primeiro lugar, por ter trabalhado como assessor especial de Leitão Abreu, ministro da Casa Civil do governo Figueiredo; em segundo, por ter sido um dos raros intelectuais públicos brasileiros que defendia posições liberais na década de 80, com direito a polêmicas com acadêmicos de esquerda como Marilena Chauí, José Arthur Giannotti e Ricardo Musse; finalmente, por ter escrito boa parte do discurso de posse de Fernando Collor de Mello, além da base programática do Partido Social Liberal Brasileiro que o ex-presidente pretendia fundar".
} 
Dossiê | O liberalismo social de Merquior: um contraste com o liberismo de F. A. Hayek para o contexto brasileiro (PAZ, Anderson Barbosa)

oportunidades para a expansão de uma liberdade efetiva em um país marcado pela desigualdade.

Hodiernamente, é preciso considerar que tem havido uma ampla divulgação de obras de autores liberais e liberistas no Brasil. Contudo, observa-se que não tem havido, proporcionalmente, um aumento de textos que dialoguem criticamente com essa expansão da tradição liberal a partir do contexto brasileiro. É nesse cenário que as obras de Hayek têm se popularizado. Nos últimos anos, tem havido um aumento na produção e tradução de textos liberais ligados à Escola Austríaca. O Instituto Ludwig von Mises Brasil (IMG), que se coloca como um think tank libertário brasileiro, tem se consolidado como o mais bem-sucedido influenciador liberal no meio acadêmico. Por meio de sua revista on-line, da criação de sua pós-graduação, e de publicações de obras liberistas, o IMB foi considerado como o think tank liberal mais influente fora dos EUA no âmbito digital. A Ludwig von Mises Editora (LVM), por sua vez, visa a publicar todas as obras do escritor austríaco - Mises - em português, como também as obras de escritores do libertarianismo anarcocapitalista e do conservadorismo liberal. A Amazon Brasil, por exemplo, elegeu a LVM como Editora Revelação de 2017 e a apresentou como modelo editorial (PAIM, 2018).

Pois bem, o liberalismo social que pressupõe a tradição liberal como uma cosmovisão e que percebe o Estado como promovedor, ao lado do mercado, da liberdade, faz contraste ao liberismo hayekiano que reduz o liberalismo à liberdade econômica. É, assim, que as obras de Merquior e Hayek, suas convergências e divergências, constituem-se como um objeto de estudo singular para o contexto hodierno brasileiro.

\section{Pensamento e contribuição de José Guilherme Merquior}

O pensamento e a contribuição de José Guilherme Merquior se devem à profundidade de suas análises. Em geral, seus textos versavam sobre política, o ser humano, e a arte. Conhecido no Brasil e no exterior ${ }^{3}$, Merquior faleceu antes dos cinquenta anos. Ativista político, diplomata brasileiro, sociólogo e crítico literário, José

\footnotetext{
${ }^{3}$ Para um detalhamento da vida e obra de Merquior, vide $O$ Enigma Merquior de André Singer.
} 
Dossiê | O liberalismo social de Merquior: um contraste com o liberismo de F. A. Hayek para o contexto brasileiro (PAZ, Anderson Barbosa)

Guilherme atuou na reflexão sobre vários domínios da cultura, dando uma singular contribuição ao traçar um perfil histórico-político do liberalismo até a contemporaneidade e ao considerar suas implicações para o Brasil. Tornou-se membro da Academia Brasileira de Letras em 1982, e doutorou-se em Letras pela Universidade de Paris e em Sociologia pela London of Economics and Political Science. Na década de 80, militou na imprensa, por meio de artigos no 0 Globo e no Jornal do Brasil. Tornouse um polemista ${ }^{4}$.

De jovem social-democrata, desencantou-se com as dificuldades do Estado de bem-estar social, e tornou-se um liberal nos anos 80. Crítico estatismo econômico do socialismo, assumiu o neoliberalismo, na linha de Von Mises e de Hayek, mas, com o tempo, passou para o social-liberalismo (ou liberalismo social), próximo às ideias de Raymond Aron e Ralf Dahrendorf (JAGUARIBE, 2014, p. 331). Defensor do progresso e da modernidade, e crítico do marxismo, freudismo e formalismo estético, o ensaísta brasileiro fez análises referenciais sobre vários desses temas (ROUANET, 2014, p. 306).

Devido à mudança em seu pensamento que se tornou mais favorável ao liberalismo e à modernidade, Merquior publica, em 1982, a obra A Natureza do Processo, em que se mostra convicto de que a crise da cultura ocidental pode ser superada e que o progresso econômico é possível. Nessa obra, o diplomata brasileiro investiga a natureza do processo da modernidade que, para ele, é o progresso da liberdade. Partindo do progresso industrial, o autor defende como pilares de um mundo livre a economia, a ciência e a democracia. Para ele, a sociedade tecnológica melhorou bastante a condição humana, possibilitando que as formas de agir e de fazer fossem múltiplas e heterogêneas. A sociedade industrial, por sua vez, institucionalizou e internalizou o progresso.

No mesmo livro, Merquior adota parte da crítica de Mises e Hayek ao dirigismo estatal na economia, critica os autores austríacos por seu déficit democrático, defende o livre mercado e critica a teoria da dependência. Porém, devido a sua perspectiva liberal social, Merquior qualifica a liberdade econômica pela necessidade de haver uma

\footnotetext{
4 "Atacou a psicanálise, cutucou o jornalista Paulo Francis, então o de maior evidência no país, esculhambou Caetano Veloso, ídolo da juventude intelectualizada e, acima de tudo, comprou uma briga de morte com Marilena Chaui (...), ao acusá-la de 'plágio não-doloso' do filósofo francês Claude Lefort. Marilena respondeu que era tradutora de Lefort para o português, além de ter formação comum e intercâmbio intelectual com ele, daí não fazer sentido a ideia de plágio" (SINGER, 2001).
} 
Dossiê | O liberalismo social de Merquior: um contraste com o liberismo de F. A. Hayek para o contexto brasileiro (PAZ, Anderson Barbosa)

ação do Estado na promoção de liberdade de oportunidades, aproximando os pontos de partidas, mas não os resultados. O escritor defende a democracia como método (Schumpeter) e atitude, a saber, uma postura esclarecida de participação ativa na vida social. Por fim, o autor critica os humanistas antimodernos que só conseguem apresentar o lado crítico do capitalismo. Ele termina a obra fazendo uma forte defesa de uma educação crítica e reflexiva como sendo a única maneira para libertar os espíritos livres de uma geração de intelectuais.

Já em sua obra Argumento Liberal (1983), Merquior objetiva multiplicar os ângulos de análise de conceitos e teorias de filosofia e política. Ele aposta na superioridade da argumentação liberal que pode se impor por sua maior racionalidade e objetividade (MERQUIOR, 1983, p. 12). Na primeira parte, o autor estabelece um diálogo com vários espectros do racionalismo crítico, desde Kant a Wittgenstein. No segundo momento da obra, o diplomata brasileiro teoriza sobre os aspectos centrais do liberalismo social, tecendo várias críticas aos pensamentos estadofobistas à direita e à esquerda políticas. Na terceira parte do texto, Merquior faz uma abordagem histórica sobre as formas históricas de legitimidade do poder e trata de várias teorias economicidas (contra uma economia livre do dirigismo estatal). Por fim, o autor faz uma leitura geral do pensamento literário e político na América Latina.

Sua magnum opus, O Liberalismo - antigo e Moderno de 1991 - obra que Merquior não chegou a ver publicada -, foi escrita no intervalo de quatro meses enquanto o autor ainda era embaixador no México. 0 escritor brasileiro explora o desenvolvimento da ideia de liberalismo no curso dos três últimos séculos, desde seu período clássico até as discussões neocontratualistas de Rawls, Nozick e Bobbio. Aponta para algumas inter-relações do liberalismo da Europa continental e da América Latina, pontuando como culturas nacionais específicas oferecem contribuições diferentes à bibliografia sobre o liberalismo. Esse panorama histórico-político, publicado em inglês, originalmente, teve excelente recepção no Brasil e no exterior. O político liberal Roberto Campos comenta que Raymond Aron sempre se referia a seu discípulo Merquior como "o jovem que tinha lido tudo". O diplomata brasileiro se notabilizou por sua profundidade na absorção de leituras e por suas ideias. Tornou-se um ativista, partindo de uma convicção liberal para uma pregação liberal (CAMPOS, 2014, p. 30). 
Dossiê | O liberalismo social de Merquior: um contraste com o liberismo de F. A. Hayek para o contexto brasileiro (PAZ, Anderson Barbosa)

No prefácio de O Liberalismo - antigo e Moderno, Merquior se declara comprometido com a herança e os princípios que sustentam a ideia liberal. E diz: “Este é um livro liberal sobre o liberalismo, escrito por alguém que acredita que o liberalismo, se entendido apropriadamente, resiste a qualquer vilificação" (MERQUIOR, 2014, p. 37). Nesse sentido, o ensaísta brasileiro entendia o liberalismo como uma cosmovisão forma de pensamento e um impulso estético no sentido de progresso - e ressaltava que esse modo de enxergar o mundo não pode ser reduzido a um liberismo, isto é, uma redução dos princípios liberais ao livre mercado (ROCHA, 2014, p. 318).

O político liberal Roberto Campos faz o seguinte comentário sobre o diplomata brasileiro:

Em nossas últimas conversas senti que José Guilherme se tornava cada vez mais liberista. (...) O liberista é aquele que acredita que, se não houver liberdade econômica, as outras liberdades - a civil e a política - desaparecem. (...) Nosso diagnóstico sobre a moléstia brasileira era convergente. Ao Brasil de hoje não falta liberdade. Falta liberismo. (CAMPOS, 2014, p. 29).

Não será possível ter certeza se Merquior abandonou seu liberalismo social para um liberismo. Isto é, se ele deixou de acreditar que é preciso, primeiramente, haver liberdade civil e política para se garantir a liberdade econômica, ou se passou a entender em sentido contrário. $O$ que se pode afirmar, porém, é que a reflexão e contribuição sobre um liberalismo social para o Brasil continua tendo singular importância e aplicabilidade para as escolhas políticas e econômicas pátrias.

\section{O liberalismo social de Merquior}

O liberalismo de Merquior se formou sob a égide das influências do liberalismo de esquerda de Thomas Hill Green (1836-1882), Leonard Hobhouse (1864-1929) e Keynes (1883-1946). Somam-se a isso a percepção do liberalismo humanista de Humboldt (1768-1835), a individualidade em Stuart Mill (1806-1873), e a democracialiberal de Raymond Aron (1905-1983) e Norberto Bobbio (1909-2004), e, ainda, a influência do liberismo de Hayek (FELIPE, 2018, p. 131) que ajudaram na formatação do pensamento liberal do diplomata brasileiro. 
Dossiê | O liberalismo social de Merquior: um contraste com o liberismo de F. A. Hayek para o contexto brasileiro (PAZ, Anderson Barbosa)

Em seu percurso intelectual, o liberalismo de Merquior foi-se aproximando do liberalismo sociológico de Raymond Aron e Ralf Dahrendorf. O primeiro defende um liberalismo que equilibre as liberdades negativas e a relevância do mercado, ao passo que postula uma relativa regulação estatal das relações econômicas e sociais. Dahrendorf, por sua vez, entende que o conflito social nas sociedades contemporâneas não se dá no nível das classes sociais, mas sim no que toca provisões e titularidades, que faz com que o embate se dê entre direitos adquiridos e meios para garantir-lhes. Devese, portanto, equilibrar provisões e titularidades (JAGUARIBE, 2014, p. 344-345).

Nessa esteira, Merquior passa a refletir e formatar seu liberalismo social. Seu problema é: como equalizar as aspirações libertárias e o peso da máquina social para o homem moderno? Para ele, a economia de mercado é o regime econômico que mais convém ao liberalismo, ao mesmo tempo que a igualdade deve ser levada em consideração. Desse modo, a democracia política era crucial. A liberdade econômica propicia a liberdade política, mas sacrificar esta por aquela liberdade, como na Ditadura Militar brasileira, é uma falsificação do liberalismo. Por outro lado, a liberdade econômica é precária sem o aperfeiçoamento da igualdade. O liberalismo implica o aperfeiçoamento da igualdade (ROUANET, 2014, p. 364).

Com efeito, o funcionamento do mercado não tem a competência, por si só, de prover tudo que uma sociedade necessita. Como o mercado se rege por critérios de eficiência e rentabilidade, não de justiça e equidade, ele cria riqueza, mas não a distribui competentemente. Por isso, é preciso corretivos dos efeitos do mercado, sem que o danifique. O livre mercado é apenas insuficiente para certos fins do homem, notadamente, reduzir suas desigualdades de ponto de partida que existem entre indivíduos devido ao berço ou educação. E, como é uma base institucional, o mercado, por si, não garante eficiência econômica (MERQUIOR, 1982, p. 55).

A ação estatal corretiva que visa a mitigar as desigualdades dos pontos de partida deve atuar em prol da liberdade de oportunidades. É a liberdade de perseguir aspirações, sejam grupais sejam individuais, conforme a vontade de viver como a cada um lhe apraz. Esse livre arbítrio se fundamenta no crescimento da divisão do trabalho e na afluência que tal crescimento assegura, crescentemente, em doses desiguais, ao conjunto societal. Assim, a liberdade de aspirações se transformou em liberdade de oportunidade, em que o indivíduo orienta toda ou grande parte de sua vida (MERQUIOR, 
Dossiê | O liberalismo social de Merquior: um contraste com o liberismo de F. A. Hayek para o contexto brasileiro (PAZ, Anderson Barbosa)

1982, p. 76). Portanto, a liberdade de oportunidades requer dois aspectos: o desenvolvimento econômico e a institucionalização de direitos sociais. Tal liberdade deve levar a mais igualdade, que, para o ensaísta brasileiro, significa supressão de privilégio, e não um igualitarismo em que a igualdade é um valor-fim (MERQUIOR, 1982, p. 103). Liberdade, igualdade e eficiência formam o tripé de um liberalismo social.

Dessa forma, a liberdade é meio para alcançar o bem comum. Deve haver participação política e pluralismo. Merquior parte da liberdade individual, não da igualdade social. A igualdade é uma ferramenta para ampliar a liberdade pessoal. Mais liberdade proporciona mais oportunidades justas. O cientista político brasileiro defende um reformismo moderado, de centro-esquerda do PMDB. Busca oferecer uma via média entre o estatismo da esquerda e a estadofobia dos neoliberais. O Estado deve ser um promotor do bem-estar coletivo. Para tanto, é preciso diminuir o Estado brasileiro para redefinir suas funções em favor da sociedade e do planejamento sem estatismo. É necessário um Estado menor, porém mais estrategista (FELIPE, 2018).

Assim, Merquior defendia uma perspectiva liberal ao reconhecer a individualidade, ao passo que se inclinava em favor do lado social devido à preocupação por uma maior igualdade de oportunidades. Deve haver a manutenção dos princípios liberais, um ambiente para reformas do aparelho estatal e mais garantia de direitos sociais. O Estado deve promover as condições propícias à vida moral, gerando virtude cívica e auto-cultivo. Com isso, direitos sociais e progresso econômico estão relacionados entre si. A economia é a mola central do progresso. Quanto maior crescimento econômico, mais benefícios sociais são possíveis. Merquior alerta que a coerção do Estado não é o único obstáculo à liberdade, posto que barreiras econômicas e sociais também impedem a liberdade. Isso legitima a ação do Estado na tentativa de mitigar as desigualdades, promovendo o exercício da liberdade em prol do bem comum. O liberalismo social é a única doutrina política contemporânea que possibilita o ideal democrático (FELIPE, 2014).

Nesse sentido, Merquior entendia que a dialética entre mais liberdade e o desejo por mais igualdade, fortalece, mais do que enfraquece, a liberdade:

A nossa sociedade permanece caracterizada por uma dialética contínua, embora sempre em transformação, entre o crescimento da liberdade e o 
Dossiê | O liberalismo social de Merquior: um contraste com o liberismo de F. A. Hayek para o contexto brasileiro (PAZ, Anderson Barbosa)

ímpeto em direção a uma maior igualdade - e disso a liberdade parece emergir mais forte do que enfraquecida (MERQUIOR, 2014, p. 264).

A ação estatal, a partir da perspectiva de Merquior, se fundamenta na noção de que há vários domínios em que as carências da sociedade e os problemas de formação do capital demandam a intervenção do Estado, inclusive para que o mercado possa se desenvolver e funcionar. As alternativas maniqueístas que idolatram ou desqualificam o Estado são simplistas. O que importa são as modalidades. Não é possível decidir antecipadamente, com base em uma variável única e genérica, uma sentença positiva ou negativa da ação do Estado. Retirar a ação do Estado em países em desenvolvimento é o caminho para injustiça e estagnação (MERQUIOR, 1983, p. 123). É preciso ampliar o Estado de Direito, já que o problema político brasileiro não é a hipertrofia do Estado, mas sim a persistência de suas formas patrimonialistas. O mal são certas formas de apropriação do Estado. Na esteira do sonho de Joaquim Nabuco, o ensaísta brasileiro dizia que não se deve jogar a sociedade contra o Estado, mas transformá-lo para que se converta de império à nação (MERQUIOR, 1983, p. 128-129).

Em sua última conferência, realizada em Sorbonne, em Paris, pouco antes de morrer, Merquior faz um percurso histórico de projetos nacionais à brasileira. $\mathrm{O}$ primeiro deles foi o projeto "Andrada" - de José Bonifácio de Andrada e Silva -, que entendia ser o primeiro projeto liberal oligárquico; em seguida, o projeto do jacobinismo positivista - inspirado em Benjamim Constant - a que se opôs a democracia dos fazendeiros; mais adiante, o projeto getulista modernizador e autoritário, seguido pelo semibismarckismo de Kubitschek, chegando à modernização autoritária do regime militar. E conclui que o Brasil deve buscar estabelecer um neocapitalismo produtivo, isto é, o fim da relação entre senhorismo capitalista e o Estado patrimonial. Deve-se afastar o estatismo e torná-lo estrategista. Para tanto, é preciso refuncionalizar o Estado, a saber, torná-lo promotor de desenvolvimento e protetor das camadas pobres da população (MERQUIOR, 2001).

Em suma, seu liberalismo social, no âmbito teórico, visa a conciliar a liberdade e a igualdade, inclinando-se por mais participação política, ao mesmo tempo que defende uma visão mais nobre do ser humano. Na prática, Merquior adere limitadamente ao livre mercado, pois entende que o Estado deve intervir para promover igualdade de 
Dossiê | O liberalismo social de Merquior: um contraste com o liberismo de F. A. Hayek para o contexto brasileiro (PAZ, Anderson Barbosa)

oportunidades e estimular a liberdade positiva (FELIPE, 2015, p. 227). Assim, “Merquior sustentava um liberalismo de equilíbrios entre a maximização da liberdade e uma ampla exigência de equidade social" (JAGUARIBE, 2014, p. 348). Essa perspectiva do liberalismo converge em alguns pontos com o pensamento de Hayek, ao mesmo tempo que constitui com esse antíteses irreconciliáveis que os afastam entre si.

\section{Linhas gerais do liberismo de F. A. Hayek}

A tradição neoliberal começou no auge do intervencionismo governamental, durante a Segunda Guerra Mundial. Porém, só na década de 1980, após fracassadas as experiências coletivistas, a saber, o nazismo e o comunismo, e uma dirigista keynesianismo - o neoliberalismo chegou ao poder político com as eleições de Margaret Thatcher (1925-2013) e Ronald Reagan (1911-2004), respectivamente, primeira ministra britânica e presidente dos Estados Unidos da América. Em sequência, a síntese do liberalismo político com o econômico formou o capitalismo democrático que busca se universalizar como forma definitiva de governo (CAMPOS, 2014, p. 22-23). Dessa maneira, o neoliberalismo destronou o keynesianismo, o estatismo assistencial, o planejamento dirigista e a social democracia. Porém, no contexto brasileiro, Campos entende que a social democracia continuou sem ser vista como o último reduto dirigista, mas sim como o primeiro capítulo do liberalismo (CAMPOS, 2014, p. 24-25).

A importância de Friedrich von Hayek (1899-1992) é imensa ${ }^{5}$, visto que sua obra influenciou a economia, filosofia, política e o Direito ${ }^{6}$. Foi o mais proeminente aluno de Mises. Ele ampliou e reformulou vários pontos da obra de seu professor, tornando-se influente ao aplicar os princípios do livre mercado a várias áreas da vida, inclusive, ao Estado de Direito. Sua principal contribuição foi a de legitimar a coerção do Estado, em um sistema de ordem espontânea de mercado, no respeito ao direito de mercado ou direito privado, isto é, Hayek repensa como e qual deve ser a natureza das intervenções do Estado na economia. O Estado de Direito é o meio de salvaguardar a liberdade individual contra as intervenções do Estado e de outros indivíduos.

\footnotetext{
5 "As ideias de Hayek formam um sistema que abrange uma visão da natureza humana, uma concepção do escopo e limites da capacidade para a reflexão consciente e dos usos do conhecimento na sociedade" (GRAY, 1980, p. 119, tradução nossa).

${ }^{6}$ Para um resumo biográfico de F. A. Hayek, vide Huerta de Soto, A Escola Austríaca, p. 107-111.
} 
Dossiê | O liberalismo social de Merquior: um contraste com o liberismo de F. A. Hayek para o contexto brasileiro (PAZ, Anderson Barbosa)

O escritor austríaco, em seu livro O Caminho da Servidão de 1944, argumenta contra toda forma coletivista de política estatal que interfere na economia e na sociedade. O Ocidente se sustenta no individualismo que tem por características o respeito pelo indivíduo como ser humano, reconhecendo suas preferências e opiniões individuais, e a convicção de que é desejável que o indivíduo aprimore seus dotes e inclinações pessoais (HAYEK, 2010, p. 40). Ele defende que a racionalidade econômica só se desenvolveu ao ganhar autonomia da política por meio da influência do pensamento liberal, mas que esse caminho havia sido abandonado, tanto por seus erros internos quanto por seus resultados externos que não preencheram as expectativas da sociedade. Tomou-se, por meio da retórica do socialismo democrático, o caminho da servidão.

Com efeito, o autor austríaco propõe uma revisão e resgate dos princípios liberais. Nessa reformulação, o papel do Estado, regido por normas previamente estabelecidas e publicizadas, passa a ser o de possibilitar a previsibilidade do exercício do poder coercitivo e a segurança jurídica dos atos individuais. O Estado de Direito impede que o governo anule os esforços individuais por meio de atos administrativos unilaterais. Como é impossível evitar totalmente a coerção ${ }^{7}$, o Ocidente delegou ao Estado o seu monopólio que se legitima se, conforme as normas preestabelecidas, impedir a coerção exercida entre os indivíduos. O Estado estabelece alguns limites legais, mas o indivíduo decide livremente os fins que deve empreender sua vida e recursos, como também valora o que lhe é de maior ou menor importância. Além disso, tal ente estatal deve dispor de uma estrutura legal que limite o mercado quando necessário, criando, assim, um ambiente propício a manutenção do livre mercado.

Dessa maneira, pelo lado econômico, o Estado deve estabelecer normas gerais e abstratas para que o indivíduo possa elaborar seus planos com condições de prever as ações estatais. Sob o aspecto moral ou político, as normas devem ser feitas para serem aplicadas a circunstâncias não previsíveis em detalhes, de modo a garantir a imparcialidade do legislador (HAYEK, 2010, p. 92-93). Essa configuração é incompatível com qualquer atividade governamental que vise a uma igualdade material ou a um ideal

\footnotetext{
7 Para Hayek, a coerção é quando um indivíduo é obrigado a agir segundo a vontade de outros em busca dos objetivos da pessoa a quem serve (HAYEK, V. I, 1985).
} 
Dossiê | O liberalismo social de Merquior: um contraste com o liberismo de F. A. Hayek para o contexto brasileiro (PAZ, Anderson Barbosa)

de justiça distributiva. O controle econômico do Estado implica o cerceamento de todos os meios para alcançar os fins escolhidos pelo indivíduo.

O filósofo econômico entende que o Estado de Direito ${ }^{8}$ só evoluiu durante a era liberal para salvaguardar e concretizar as normas em prol da liberdade (HAYEK, 2010, p. 96). Nesse formato de Estado, deve haver uma limitação do campo legislativo, restringindo-o às normas gerais do Direito formal e excluindo toda legislação que discrimine indivíduos. O fundamento da liberdade econômica é o de que ela constitui o requisito prévio de qualquer outro tipo de liberdade e deve, junto com a liberdade de ação, possibilitar os riscos e responsabilidades inerentes à liberdade.

Em outra obra, Hayek (2017) sustenta que a competição é um procedimento de descoberta que é intrínseca a toda evolução, aumentando sua eficiência. Tal percurso histórico é fruto de um processo de tentativa e erro, de experimentação. Dessa maneira, é uma presunção fatal pensar que a capacidade de adquirir habilidades se origina da razão. Tanto esta última quando a moralidade são resultados de um processo de seleção evolutiva9 ${ }^{9}$ Logo, é uma presunção o Estado estabelecer-se como planejador central de um mercado. Devido à complexidade deste último, o socialismo é impraticável.

Para garantir a liberdade a um número máximo de pessoas, deve-se restringir uniformemente a liberdade de todos por meio de regras abstratas que impeçam a coerção arbitrária ou discriminatória de ou por outros indivíduos e evitem cada um de invadir a esfera de liberdade do outro. Substituem-se, com isso, os fins comuns ou comunitários por regras abstratas comuns. O Estado deve apenas fazer valer tais regras abstratas e, através delas, proteger o indivíduo contra a coerção ou a invasão de sua esfera de liberdade por outros. Tal obediência a regras abstratas comuns possibilita o campo para mais liberdade e diversidade, e isso traz mais ordem (HAYEK, 2017, p. 88). Em suma, a ordem de mercado é espontânea ao conciliar diferentes objetivos em benefício mútuo dos indivíduos. Ademais, as normas formais, que são gerais e abstratas, estabelecem limites ao que não pode ser feito, mas não dispõem o que os indivíduos

\footnotetext{
8 O Estado de Direito visa a garantir a cada cidadão a possibilidade de projetar sua vida como quiser. Sua validade é mais política do que jurídica, pois faz frente ao Estado social e preserva os ideais jurídicos liberais. Essa noção de Estado de Direito formulada por Hayek prevaleceu nas décadas pós-1940 (SANTORO, 2005, p. 30).

9 "O direito, o mercado, a moral, o dinheiro, a linguagem e o conhecimento seriam subordens espontâneas que (...) surgiram da evolução lenta e gradativa das tradições culturais fundadas nas experiências compartilhadas, mas não da reflexão humana" (NOGUEIRA, 2014, p. 523).
} 
Dossiê | O liberalismo social de Merquior: um contraste com o liberismo de F. A. Hayek para o contexto brasileiro (PAZ, Anderson Barbosa)

podem fazer. Além disso, a sociedade é mantida por laços puramente econômicos que fundamentam o vínculo social.

A partir de 1949, Hayek passou a dedicar-se ao estudo dos condicionamentos jurídicos e institucionais de toda a sociedade livre, produzindo, nas três décadas seguintes, três obras bastante influentes, a saber, Os fundamentos da liberdade e a trilogia Direito, legislação e liberdade (HUERTA DE SOTO, 2010, p. 123). Nessa primeira obra, o economista austríaco defende, em face ao poder de coerção do Estado que pode reduzir as possibilidades de escolha dos indivíduos, que normas gerais devem ser estabelecidas para permitir aos cidadãos delimitar o conteúdo de sua esfera privada (HAYEK, 1983, p. 153).

Para Hayek, a coerção estatal se dá por meio de uma legislação que é a determinação unilateral do órgão diretivo da ação a ser praticada, enquanto que a lei é a norma geral - tem caráter abstrato, negativo, instrumental - que o agente considera em sua decisão (HAYEK, 1983, p. 165). Quem deve governar são as leis e não os governantes por meio da legislação. Para o autor austríaco, a lei - aplicável a todos por igual - apenas delimita o campo de atuação individual. À medida que o intervencionismo econômico se expande, notadamente em um regime socialista, as leis deixam de funcionar como normas de referências para os indivíduos e se tornam uma legislação. Os indivíduos deixam de obedecer a legislação para sobreviver. A justiça torna-se corrompida ao se tornar fruto de uma avaliação arbitrária de um órgão político ou de um juiz que não mais julga comportamentos, mas sim resultados. Essa justiça social, que avalia os resultados, é injusta (HUERTA DE SOTO, 2010, p. 124-125). O que importa é se a conduta humana é justa ou injusta, e não se os resultados específicos são justos ou não. Logo, a justiça é a compatibilidade do ato do indivíduo com o sistema de normas universais que regem a sociedade (NOGUEIRA, 2014, p. 531-532).

A partir de uma visão evolucionista ${ }^{10}$ das relações sociais, Hayek entende que a maioria das normas evoluiu por um processo gradual de tentativa e erro formando o

\footnotetext{
${ }^{10}$ Como a mente humana é autônoma, o conhecimento do ser humano e sua valoração, para Hayek, não podem ser determinados ou preditos. Assim, há certa verdade no conhecimento que sobrevive a um natural processo de seleção. A mente humana é um produto da evolução cultural, de modo que ela permanece parcialmente desconhecida e o ser humano não pode conhecer os aspectos inalteráveis de sua natureza. A mente tem autonomia até onde o conhecimento é possível. Portanto, o conhecimento do ser humano é limitado e consolidado por tradições e herança de uma evolução social (GRAY, 1980, p. 120124).
} 
Dossiê | O liberalismo social de Merquior: um contraste com o liberismo de F. A. Hayek para o contexto brasileiro (PAZ, Anderson Barbosa)

conteúdo da norma. A teoria econômica explica o ajustamento mútuo das atividades espontâneas dos indivíduos gerado pelo mercado. Compreender esse mecanismo é fundamental pois deve condicionar a elaboração das normas gerais que restringem a ação individual (HAYEK, 1983, p. 177). Assim, as leis e instituições têm origem evolutiva ao incorporar experiências e informações ao longo de gerações. A coordenação social é fruto desse processo espontâneo. A função empresarial, que descobre e elimina os desajustes sociais, abre oportunidades de lucro (HUERTA DE SOTO, 2010, p. 124-126).

Sobre o Estado ${ }^{11}$, o escritor austríaco entende que é o caráter e não a magnitude da atividade governamental que importa, posto que uma economia de livre mercado pressupõe certas atividades por parte do Estado, "desde que compatíveis com o funcionamento do mercado" (HAYEK, 1983, p. 269). Logo, as atividades do Estado prejudiciais ao mercado devem ser excluídas, enquanto que as que the favorecem devem ser mantidas. Um governo que ativamente se envolve com os problemas econômicos e estimula as forças espontâneas do mercado é mais desejável do que aquele pensado sob o princípio do laissez-faire ${ }^{12}$. O Estado de Direito é o critério que serve para distinguir entre medidas compatíveis com um sistema de mercado e as que não.

De maneira resumida, em Os fundamentos da liberdade, Hayek desafia a interdição analítica da filosofia política, enquadra o mercado e o progresso em um quadro evolucionista e apresenta o mercado como um sistema de informação sem rival (MERQUIOR, 2014, p. 227-228). O livre mercado é o veículo para descentralizar o conhecimento. Para ele, a intervenção do Estado é negativa já que desarranja a rede de informações do sistema de preços e reduz o escopo da experiência econômica, de forma que, por sua complexidade, a economia não pode ser dominada pela razão humana. A intervenção estatal deve ser evitada, posto que o kosmos (ordem criativa espontânea evolução social) supera a táxis (ordem criada pelas utopias racionalistas - planejamento humano).

\footnotetext{
11 “O propósito do direito para Hayek é salvaguardar a liberdade individual, através da proteção de expectativas consideradas legítimas" (NOGUEIRA, 2014, p. 528). "A finalidade do direito é dar concretude às expectativas legítimas dos indivíduos, pela delimitação dos limites protegidos de cada um, ou seja, pela delimitação da propriedade" (NOGUEIRA, 2014, p. 529).

12 "A velha fórmula do laissez-faire, ou da não intervenção, não nos propicia um critério adequado para distinguirmos entre o que é e o que não é admissível num sistema livre” (HAYEK, 1983, p. 279).
} 
Dossiê | O liberalismo social de Merquior: um contraste com o liberismo de F. A. Hayek para o contexto brasileiro (PAZ, Anderson Barbosa)

Já em sua clássica trilogia, Direito, legislação e liberdade, Hayek postula que o governo tem duas funções, a dizer, prover uma estrutura para o mercado e prover serviços que este último não pode. Além disso, ele entende que só com a liberdade econômica, as outras liberdades - civil e política - podem ser mantidas. Hayek defende que para manter o livre mercado as pessoas devem abandonar sua tendência inata para agir em conjunto na busca de objetivos comuns, visto que a civilização é uma sociedade abstrata que se baseia em normas aprendidas, e não na busca de finalidades comuns. 0 mercado implica um respeito por normas, mas não a construção de uma solidariedade espontânea. O homem primitivo era um ser supersocializado, mas, com a marcha da civilização, o indivíduo aprendeu a controlar seus instintos e tomar distância de sentimentos tribais, de comunidade e de comunalidade (MERQUIOR, 2014, p. 228-230).

O economista austríaco propõe que a economia possibilita o relacionamento entre as normas jurídicas e a ordem global (outras esferas da realidade social), visto que ela desenvolveu uma técnica teórica para estudar essas ordens abstratas espontâneas, devendo ser aplicada para outras ordens além da de mercado. A economia é a única ordem que alcança toda a sociedade humana (HAYEK, 1985, v. I, p. 133). Para ele, existem dois tipos de normas de conduta, a saber, o nomos (lei $)^{13}$, normais gerais que derivam das condições de uma ordem espontânea ${ }^{14}$ e que não é cartesianamente criada pelo homem mas apenas descobertas, ex. direito à propriedade e à vida, e a thesis (legislação), normas específicas intencionalmente formuladas para atender a propósitos específicos, sendo invenções arbitrárias da mente planejadora do organizador, ex. direito do trabalho e eleitoral. Este último tipo é criado pelo governo, enquanto o primeiro é fruto de um processo de erros e acertos que ordenam uma sociedade de livre mercado (HAYEK, 1985, v. I, p. 141).

Nesse quadro, a sociedade livre é aquela em se combina kósmos-nomos, isto é, ordem espontânea mais normas gerais, resultando na ordem liberal ${ }^{15}$ de livre mercado

\footnotetext{
13 Lei para Hayek "refere-se à regra universal, de conduta justa, geral, abstrata, não deliberadamente criada pelo homem, não necessariamente escrita e aplicada a um número indistinto de casos futuros, sem qualquer correspondência com circunstâncias específicas de temo e lugar" (NOGUEIRA, 2014, p. 527).

14 "A ordem decorre de um ajustamento de expectativas a circunstâncias que, embora contingentes e desconhecidas, são passíveis de se revelarem eficazes ou, até mesmo, corretas" (NOGUEIRA, 2014, p. 522).

15 “É precisamente a presença do conflito moral e das tradições intelectuais em nossa sociedade que garante a instituição de uma ordem liberal. Essa ordem providencia um quadro neutro em que a
} 
Dossiê | O liberalismo social de Merquior: um contraste com o liberismo de F. A. Hayek para o contexto brasileiro (PAZ, Anderson Barbosa)

e Estado de Direito. No outro espectro, tem-se a sociedade totalitária que combina taxisthesis, a saber, uma ordem criada deliberadamente com normas específicas que comandam a ação dos indivíduos, resultando em controle da economia e em comandos para atingir determinados fins (NOGUEIRA, 2014, p. 525). Não há uma terceira alternativa. Quando o Direito público adentra o privado, pavimenta-se o caminho rumo a socialização do direito, em que os governos tutelam os indivíduos como uma coisa a ser administrada para atingir resultados específicos (NOGUEIRA, 2014, p. 529).

Na visão de Hayek, quando o governo intervém para promover a justiça social, apenas proporciona uma miragem por meio de normas específicas que buscam um suposto futuro bem-estar. Hayek se coloca contra os arranjos do liberalismo social e da social democracia. No primeiro, kósmos-thesis faz com que a economia de mercado seja dirigida por comandos dirigistas. Distorcem-se as informações e inibe-se a competição. Demandar-se-ia mais intervenção, convergindo para um intervencionismo econômico pleno (taxis-thesis). Por outro lado, em um quadro taxis-nomos - social democracia conjugar-se-ia o liberalismo político com o controle econômico. Os comandos dos dirigentes substituiriam as normas impessoais do mercado por ordens dirigistas, seguindo o curso taxis-thesis ou, na linguagem hayekiana, o caminho da servidão (NOGUEIRA, 2014, p. 525-526).

Para o autor austríaco, como a justiça é um fenômeno social, adjetivá-la com a noção social é uma redundância. Essa ideia é uma concepção moral que se quer impor à sociedade, sem relação com a justiça. Hayek entende que a concepção de uma justiça social é a que mais ameaça os valores de uma civilização que se pauta na liberdade. Quando o Estado tenta intervir em prol da justiça social, o arbítrio de alguns burocratas se impõe sobre a vontade dos indivíduos que, por sua vez, perdem sua própria liberdade (NOGUEIRA, 2014, p. 534-535). Logo, os direitos sociais e os direitos coletivos e difusos apenas são privilégios direcionados a grupos específicos. Essa liberdade positiva promovida pelo Estado provém de um pensamento socialista que causa injustiça, já que viola a liberdade legítima, a saber, a negativa ${ }^{16}$ (NOGUEIRA, 2014, p. 516). A liberdade a

competição pacífica pode ocorrer entre formas rivais de vida social, em que os que melhor se adaptem às mudanças de circunstâncias possam prevalecer" (GRAY, 1980, p. 125-126).

${ }^{16}$ Para Hayek, liberdade é ausência de coerção. Ela é negativa, isto é, o indivíduo não está obrigado por quem detém o poder de coerção a fazer o que não deseja, nem impedido de fazer o que quer (HAYEK, 1983). 
Dossiê | O liberalismo social de Merquior: um contraste com o liberismo de F. A. Hayek para o contexto brasileiro (PAZ, Anderson Barbosa)

ser garantida pelo Estado deve ser tão somente negativa e impessoal ao proporcionar ao indivíduo a amplitude para que busque seus próprios objetivos.

Parece que Hayek sobrepõe a economia às outras esferas da realidade social. Essa perspectiva liberal parece considerar central o aspecto econômico. Face a essa racionalidade, o ensaísta brasileiro Merquior apresenta seu liberalismo social a partir do contexto brasileiro. Para este último autor, a ação estatal não é um mal em si e sua ação, especialmente em países não-desenvolvidos, deve buscar igualar oportunidades na promoção de mais liberdade. Porém, ambos os autores concordam em sua crítica ao dirigismo estatal. Pergunta-se, então, em que se dão as convergências e divergências do liberalismo social de Merquior e o liberismo de Hayek?

\section{Contrastes entre o liberalismo social de Merquior e o liberismo de F. A. Hayek}

Merquior, na linha de Hayek, entende que a confiança na liberdade não se fundamenta na previsibilidade das consequências dos atos humanos, mas sim na crença que, ainda que negativas algumas das consequências, o balanço final será positivo. Nesse sentido, o progresso, que é um crescimento espontâneo e cumulativo, não pode ser planejado, nem submetido a uma prévia determinação, em tese, sustentada em nobres ideais. Como a mente é um produto da cultura, conforme ensino de Hayek, o racionalismo e intelectualismo não são possíveis para se garantir o progresso. Logo, "o progresso é, como a evolução, um incessante e bem-sucedido processo de adaptação, não um construto laboratorial” (MERQUIOR, 1982, p. 36).

Para o sociólogo brasileiro, o dirigismo dos regimes socialistas não levou à aceleração do progresso nos países que os adotaram. De modo que quando há um governo dirigista, menor é a velocidade do desenvolvimento e mais clara a impressão do fracasso econômico (MERQUIOR, 1982, p. 39). A planificação minuciosa da produção e consumo leva à insuficiência de recursos e ao estrangulamento da economia. Na mesma linha de Hayek, é preciso combater o autoritarismo do estado totalitário, como também seu antieconomismo. Em sua percepção, "as economias ocidentais estão em recessão - mas a economia soviética vive em recessão" (MERQUIOR, 1982, p. 41). O mercado possibilita o uso mais efetivo dos fatores de produção. A lei da oferta e da demanda demonstra o meio mais racional de distribuir recursos e investimentos. E o 
Dossiê | O liberalismo social de Merquior: um contraste com o liberismo de F. A. Hayek para o contexto brasileiro (PAZ, Anderson Barbosa)

lucro, que é a alma do mercado, é "o melhor indicador da minimização dos custos" (MERQUIOR, 1982, p. 50). Assim, só onde funciona o livre mercado, funciona a economia.

Outro ponto convergente com Hayek, dá-se na noção de Estado de Direito pelo qual Merquior entende que deve prevalecer o império da lei. A ordem é, em si, um bem social, e o império da lei compatibiliza o princípio da ordem com o individualismo da cultura moderna. A única autoridade legítima é a norma universal. O Estado de Direito exclui a sistemática arbitrariedade e prepotências dos dirigentes estatais. Logo, o Estado floresce com o vigor da liberdade (MERQUIOR, 1982, p. 141). Nesse sentido, "o mundo liberal é uma ordem monocrática - uma sociedade colocada sob o império da lei, onde todo poder possa ser experimentado como autoridade e não como violência" (MERQUIOR, 1983, p. 87). Na esteira hayekiana, o autor brasileiro entende que a ordem liberal demanda a conjunção de constitucionalismo e democratização da cidadania.

A crítica de Merquior ao neoliberalismo, inclusive a Hayek, se dá no sentido de que seus proponentes tornam o liberalismo em um neoliberismo ${ }^{17}$, isto é, uma redução do liberalismo clássico à economia. Após as fases do paleoliberalismo - liberalismo clássico - e do social-liberalismo, Merquior diz que surge a fase neoliberal. Seu maior expoente é F. A. Hayek que propõe o desmanetelamento do social-liberalismo, um retorno ao estado mínimo e à crença de que o progresso depende de uma soma nãoplanejada de iniciativas individuais. Quietismo do governo no plano da economia e legalismo no plano político-social. Para Merquior, a utopia neoliberal, de um puro e simples reino da legalidade, não atende aos impulsos democratizantes das sociedades liberais modernas. Nesse contexto, o livre mercado, por si só, não garante automaticamente liberdade ${ }^{18}$, pois não pode gerar requisitos e oportunidades suficientes para o exercício mais pleno da individualidade de vários grupos minoritários. Não se pode só confiar no mercado como garantidor de justiça. Ainda assim, não se pode suprimir o mercado (MERQUIOR, 1983, p. 94-95).

\footnotetext{
17 O filósofo italiano Benedetto Croce (1866-1952) foi o autor que introduziu uma cunha conceitual entre liberalismo e liberismo. Para ele, "enquanto o liberalismo é um princípio ético, o liberismo não passa de um preceito econômico que, tomado equivocadamente por uma ética liberal, degrada o liberalismo a um baixo hedonismo utilitário" (MERQUIOR, 2014, p. 174).

18 "A desestatização completa é, no mundo moderno, uma completa miragem - e nos países em desenvolvimento, o caminho da injustiça e da estagnação" (MERQUIOR, 1983, p. 123).
} 
Dossiê | O liberalismo social de Merquior: um contraste com o liberismo de F. A. Hayek para o contexto brasileiro (PAZ, Anderson Barbosa)

Na percepção de Merquior, o neoliberismo de Mises e Hayek propõe uma volta ao laissez-faire à medida que creem que o progresso resulta automaticamente de uma soma não-planejada de atividades individuais. Para o diplomata brasileiro, o neoliberismo é uma reprise do liberalismo clássico, pois herda suas deficiências em matéria histórica e consciência social, não sendo capaz de atender aos impulsos democratizantes das sociedades de modelo liberal. De modo localizado, Merquior chama atenção à percepção de que as exigências sociais de um país como o Brasil, em que a síntese entre democracia e liberalismo é incompleta, não pode ser atendida por um modelo liberista. Por isso, defende a retomada de um social-liberalismo ou liberalismo social. Logo, direitos civis, políticos e sociais podem coexistir em uma democracia representativa (FELIPE, 2015, p. 223).

Hayek propõe o desmantelamento do social-liberalismo, um retorno ao estado mínimo e à crença de que o progresso depende de ações não-planejadas dos indivíduos. Merquior observa que, apesar do autor austríaco adotar uma abordagem evolucionista da sociedade ao defender que o progresso e o mercado têm uma sabedoria inerente, nega que haja essa sabedoria nas instituições que reprova, como as que controlam a renda, o preço e a taxação progressiva. Não seriam tais instituições resultantes de muitas evoluções imprevistas? Além disso, se a evolução é uma tradição do kósmos, tudo, até o que embaraça o mercado e solapa a liberdade, pode ser aceito como desejável. Ademais, se a evolução é seleção, por que tantas críticas a experimentos sociais se de qualquer forma serão abandonados? (MERQUIOR, 2014, p. 231-232).

Outro ponto crítico do pensamento hayekiano observado por Merquior é que o autor austríaco adota uma noção de nomocracia, isto é, é preciso se estabelecer as regras do jogo em lugar de valores e de objetivos partilhados. Assim, a liberdade é um instrumento de progresso, de modo que o mérito do indivíduo é contribuir (inconscientemente) para a evolução social. Tal neoliberismo, como o neoevolucionismo, mina a própria ética liberal, já que valores e instituições emergem espontaneamente sem um fundamento que Ihes justifique (MERQUIOR, 2014, p. 232233). Com isso, o favorecimento do livre mercado em Hayek e a restrição da interferência da esfera pública sobre a privada põe a ética liberal - seu auto aperfeiçoamento e pluralismo - em risco (FELIPE, 2015, p. 227). 
Dossiê | O liberalismo social de Merquior: um contraste com o liberismo de F. A. Hayek para o contexto brasileiro (PAZ, Anderson Barbosa)

Ainda, na linha de Raymond Aron, Merquior critica Hayek ao considerar que a generalidade da lei não elimina seu aspecto impositivo para dados grupos sociais, posto que a lei, por mais geral que seja, exprime por vezes interesses particulares (MERQUIOR, 1983, p. 94).

Como demonstrado, Merquior e Hayek convergem em alguns pontos, a saber, na importância da liberdade econômica, na concordância sobre a teoria da ordem espontânea para explicar o progresso da sociedade moderna, e no ceticismo quanto ao racionalismo construtivista e no planejamento governamental (FELIPE, 2015, p. 227).

Porém, ambos os autores divergem. Na epistemologia, Merquior não adota as perspectivas conservadora e neo-evolucionista que marcam as obras tardias de Hayek, devido a sua crescente confiança na ciência da evolução como tradição. E, politicamente, Merquior discorda do achatamento da democracia à demarquia ${ }^{19}$ e da concepção monocrática do Estado, em que este apenas define as regras do jogo sem se importar com reivindicações mais igualitárias e substanciais (FELIPE, 2015, p. 227). Portanto, Merquior não é um neoliberal ou liberista.

\section{Considerações finais}

José Guilherme Merquior tornou-se uma figura emblemática nesse país. Respeitado membro da Academia Brasileira de Letras, tornou-se, por um tempo, idealizador do governo Collor. Sua contribuição, porém, permanece em várias áreas. Em seu percurso intelectual, como anteriormente salientado, partiu de um liberismo da linha de Mises e Hayek e, depois, tornou-se um social liberal. Seu liberalismo social, com sua crítica ao patrimonialismo e ao personalismo brasileiro, buscava equilibrar a atuação do Estado face ao livre mercado. Crítico do reducionismo liberista de um Estado de Direito para salvaguardar o livre mercado, conforme apontado no pensamento de Hayek, entendia pela necessidade de algum grau de ação estatal na economia para o benefício social. Logo, Merquior não era nem conservador nem neoliberal, mas sim um liberal social.

\footnotetext{
${ }^{19}$ Demarquia é uma governança das leis em que são formuladas por um número de comitês competentes, burocratas, que não são responsáveis perante ninguém, tendo sua legitimidade derivada da norma.
} 
Dossiê | O liberalismo social de Merquior: um contraste com o liberismo de F. A. Hayek para o contexto brasileiro (PAZ, Anderson Barbosa)

Nesse sentido, o ensaísta brasileiro e o economista austríaco se aproximam devido à crítica aos regimes socialistas e à adoção metodológica da ordem espontânea de mercado. O sociólogo brasileiro, porém, tornou-se crítico do liberismo do autor austríaco. Este, por sua vez, formulou críticas a Estados promovedores de oportunidades e, mais adiante, colocou o livre mercado como determinante das outras esferas sociais. Enquanto que o cientista político brasileiro, refletindo em um contexto de uma nação de história desconstituída de revoluções burguesas, não-desenvolvida e pré-liberal, percebia que a necessidade do Estado na criação de oportunidades ia além de manter e proporcionar um ambiente de negócios. O desenvolvimentismo de Merquior pressupõe um liberalismo em que o Estado intervém na economia para o bemestar social.

A influência das ideias do diplomata brasileiro se fez presente nos governos seguintes à sua morte. Os mandatos de Fernando Henrique Cardoso e de Luiz Inácio Lula adotaram práticas políticas social-liberais influenciadas por Merquior (FELIPE, 2018), às vezes, mais liberalizantes, às vezes, mais sociais, porém, tendo em comum a noção de intervenção estatal reformista em que a liberdade de mercado coexiste com a ação do governo em prol de criação de oportunidades. Portanto, o liberalismo social merquioriano parece permanecer face ao liberismo de Hayek como um postulado importante para o avanço da justiça em um país como o Brasil.

\section{Bibliografia}

CAMPOS, Roberto. Merquior, o Liberista. In.: O liberalismo - antigo e moderno. - 3. ed. - São Paulo: É Realizações, 2014, p. 19-31.

FELIPE, Kaio. A ideia de liberalismo social no pensamento político de José Guilherme Merquior. IX Encontro da ABCP: Pensamento Político Brasileiro, 2014.

Merquior, um liberista? Uma comparação entre o pensamento liberal de José Guilherme Merquior e o de Friedrich von Hayek. MISES: Revista Interdisciplinar de Filosofia, Direito e Economia. Volume III, Número 1 (Edição 5), 2015, p. 215-228.

Para além do neoliberalismo e da social-democraica: uma análise do liberalismo social de José Guilherme Merquior. Em Tese: Programa de Pós-Graduação em Sociologia Política, v. 15, n. 1 (parte II), 2018, p. 129-151.

GRAY, John N. F. A. Hayek on Liberty and Tradition. Oxford University: The Journal of Libertarian Studies, vol. IV, $\mathrm{n}^{\circ}$ 2, 1980. 
HAYEK. F.A. Os fundamentos da liberdade. - São Paulo, Visão, 1983.

Direito, legislação e liberdade: uma nova formulação dos princípios liberais de justiça e economia política. V. I: Normas e Ordem. São Paulo: Visão, 1985.

Direito, legislação e liberdade: uma nova formulação dos princípios liberais de justiça e economia política. V. II: A miragem da justiça social. São Paulo: Visão, 1985.

O caminho da servidão. - São Paulo: Instituto Ludwig von Mises Brasil, 2010.

. Os erros fatais do socialismo. - 1. ed. - Barueri: Faro Editorial, 2017.

HUERTA DE SOTO, Jesus. A Escola Austríaca: mercado e criatividade empresarial. - São Paulo: Instituto Ludwig von Mises Brasil, 2010.

JAGUARIBE, Hélio. Merquior e o Liberalismo. In.: O liberalismo - antigo e moderno. - 3. ed. - São Paulo: É Realizações, 2014, p. 331-349.

MERQUIOR, José Guilherme. A natureza do processo. - Rio de Janeiro: Nova Fronteira, 1982.

. O Argumento Liberal. - Rio de Janeiro: Nova Fronteira, 1983.

. O Brasil no limiar do século 21. Folha se São Paulo. 2001. Disponível em

https://www1.folha.uol.com.br/fsp/mais/fs1507200107.htm. Acesso em 13 de junho de 2019.

O liberalismo - antigo e moderno. - 3. ed. - São Paulo: É Realizações, 2014.

NOGUEIRA, Jorge Henrique de Saules. O Direito como Salvaguarda da Liberdade: elementos da Teoria do Direito de F. A. Hayek. MISES: Revista Interdisciplinar de Filosofia, Direito e Economia. Volume II, Número 2 (Edição 4), 2014.

PAIM, Antônio. História do liberalismo brasileiro. - 2a ed. rev. e ampl. - São Paulo: LVM, 2018.

ROCHA, João Cezar de Castro. A visão do mundo de José Guilherme Merquior: esta reedição. In.: O liberalismo - antigo e moderno. - 3. ed. - São Paulo: É Realizações, 2014, p. 311-324.

ROUANET, Sérgio Paulo. Merquior: obra política, filosófica e literária. In.: 0 liberalismo - antigo e moderno. - 3. ed. - São Paulo: É Realizações, 2014, p. 360-370.

SANTORO, Emilio. Estado de Direito e interpretação: por uma concepção jusrealista e antiformalista do estado de direito. Porto Alegre: Livraria do Advogado Ed., 2005.

SINGER, André. O enigma Merquior. Folha se São Paulo. 2001. Disponível em https://www1.folha.uol.com.br/fsp/mais/fs1507200105.htm. Acesso em 13 de junho de 2019. 